\title{
The influence of mineral fertilizers on the mass of plant-root residues of grain crops on chernozem soils of the Western Siberia
}

\author{
D.V. Eremina*
}

Federal State Budgetary Educational Institution of Higher Education State Agrarian University of the Northern Trans-Urals, city of Tyumen, Russia

\begin{abstract}
The influence of various levels of mineral nutrition on the accumulation of plant-root residues of spring wheat and oats in the conditions of the forest-steppe zone of Western Siberia is studied. The natural agricultural background of leached chernozem was taken as a control. The research was carried out at the station of the Department of Soil Science and Agrochemistry of the State Agrarian University of the Northern Trans-Urals. In the experiment, various doses of mineral fertilizers were used, ensuring the yield of grain crops from 3.0 to $6.0 \mathrm{t} / \mathrm{ha}$. It was found that the mass of plant-root residues of spring wheat and oats has no significant differences and depends on the level of mineral nutrition. On the natural agricultural background, the mass of plant-root residues is 3.24-3.88 t/ha. Fertilization increases the yield of grain crops to $6.0 \mathrm{t} / \mathrm{ha}$, and also increases the amount of plant-root residues: spring wheat - 4.47; oats $-6.04 \mathrm{t} / \mathrm{ha}$. Increasing the doses of mineral fertilizers reduces the ratio of yield to the mass of plant-root residues from 1:1.6 to 1:1.10 units. It was found that almost half of the root system of spring wheat and oats is located in a layer of $0-10 \mathrm{~cm}$, while the share of roots in a layer of 30-40 $\mathrm{cm}$ accounts for no more than $16 \%$ of the mass.
\end{abstract}

\section{Introduction}

The Western Siberia is a promising region in terms of agriculture, despite the harsh climate. Until the 60s of the XX century, it was not considered a zone of cultivation of commercial grain and other crops. Basically, grain crops were grown for animal husbandry, which was a priority in Siberia [1,2]. With the development of domestic breeding, new varieties of grain crops have appeared that are able to form grain with high quality indicators [3, 4]. The Siberian school of agriculture was also actively developing, which considers the unfavorable soil and climatic conditions of the region and allows growing even such heatloving crops as soybeans and corn $[5,6]$.

The intensification of agriculture in the Western Siberia was very active, since cheap mineral fertilizers solved one of the main problems - low yields. The soil cover in Siberia is mainly represented by gray forest and sod-podzolic soils, the fertility of which is

\footnotetext{
* Corresponding author: soil-tyumen@yandex.ru
} 
significantly lower than chernozems. The area of highly fertile soils (dark gray and chernozems) is insignificant, but these soils are also characterized by a low level of fertility, due to low biological activity [7]. Therefore, farmers in Siberia have been using high doses of fertilizers to increase yields since the $80 \mathrm{~s}$. The rejection of organic fertilizers in favor of mineral fertilizers has led to a serious deterioration of the basic properties of arable land. The humus state suffered the most, both in quantitative and qualitative terms. Since there are few long-term stationary experiments with fertilizers in Siberia, farmers faced the question of how to preserve humus reserves and at the same time increase productivity.

In recent years, we have repeatedly heard opinions that there are no negative changes in humus during the transition to the mineral fertilizer system, because the non-commodity part of agricultural crops also increases. This is especially true for plant-root residues, which are primarily humified [8].

Humus formation of soils is a modern element of soil formation, which should go on continuously. On virgin lands, all the plants growing on it serve as a source of organic carbon replenishment. On arable land, the system of receiving plant residues differs from virgin lands. This is expressed by the withdrawal of part of the plant biomass in the form of marketable products, which leads to a decrease in the intake of organic carbon into the topsoils Also, the frequency of receipt of plant residues and organic fertilizers, which are applied under fallows or tilled crops, is well expressed on arable land.

Plant-root residues of grain crops are valuable for the soil microbiota, since they contain a sufficient amount of energy and nutrients. The analysis of the literature data showed significant contradictions in the mass of plant residues of agricultural crops $[9,10]$. Their quantity depends on the varietal and biological characteristics of plants; cultivation technology and soil and climatic conditions $[11,12]$.

In areas with arid climates, plants actively increase the root system for effective absorption of soil moisture. It is also known that mineral fertilizers can have a certain influence on the biomass, thereby changing the humus formation both for the better and for the worse. As long-term stationary studies have shown, the systematic application of high doses of mineral fertilizers designed to produce 6.0 tons of spring wheat and oats in combination with the broken-down straw plow down led to a significant decrease in humus reserves in leached chernozem. Therefore, it became necessary to study the effect of increasing doses of mineral fertilizers on the biomass of plant-root residues and the nature of the distribution of the root system within the boundaries of the humus-accumulative horizon.

\section{Materials and methods}

The research was carried out at the station of the Department of Soil Science and Agrochemistry, located in the northern forest-steppe of the Tyumen region. Coordinates of the station: $59^{\circ} 09^{\prime} 36^{\prime /}$ north latitude; $65^{\circ} 19^{\prime} 53^{\prime /}$ east longitude. The station was established in 1995 and is still in use today. The soil is leached thin chernozem, medium-humus, heavyloamy. According to its agrochemical and physical and chemical properties, it corresponds to the chernozems of the Western Siberia. The organic carbon content in the $0-40 \mathrm{~cm}$ layer is on average $4.15 \%$. The exchange acidity is 5.7 units with a degree of base saturation of $92 \%$ of the cation exchange capacity.

At the station, a grain-fallow crop rotation with alternating crops is deployed in time and space: annual grasses (pea-oat mixture) - spring wheat-oats. Over the years of the station existence, crop rotation and crops have not changed. All experimental plots are fixed. The soil treatment system is a dump multi-depth one. The plowing depth for grain crops is $20-22 \mathrm{~cm}$. The cultivation system of spring wheat and oats is traditional for the forest-steppe zone of Western Siberia. 
The studies were conducted according to the following scheme. As a control, the option without the use of fertilizers was taken, the yield on the control was formed only due to natural fertility and the smell of break-down straw. Different levels of mineral nutrition were studied at the station, which were created by applying appropriate doses of fertilizers that ensure the yield of spring wheat 3.0 (N40P75); 4.0 (N100P90) 5.0 (N150P200) and 6.0 t/ha (N185P160). Fertilizers were applied under oats, respectively, N60P20; N90P40; $\mathrm{N} 150 \mathrm{P} 60$ and N200P80 $\mathrm{kg} / \mathrm{ha}$ of the active substance. The calculation of the doses of mineral fertilizers was carried out by determining the necessary amount of nutrients for the formation of the planned yield of grain crops and their actual reserves in the soil. Mineral fertilizers were applied in the spring period for cultivation before sowing.

In the experiment, the mass of plant-root residues was determined in layers to a depth of $40 \mathrm{~cm}$ with a selection step of $10 \mathrm{~cm}$. The quantity of plant and crop residues was determined by the framework method of N.Z. Stankov (frame size $30 \times 33 \mathrm{~cm}$ ). The yield of spring wheat and oats was determined by manual threshing of a sheaf collected from 1 square meter, with further recalculation into standard values $(\mathrm{t} / \mathrm{ha})$. The data of the research results were subjected to mathematical processing by the dispersion method

\section{Research results}

In the years of research (2017-2020), the average yield of spring wheat and oats on leached chernozem was $2.0 \mathrm{t} / \mathrm{ha}$ with a variation over the years ranging from 1.5 to $2.2 \mathrm{t} / \mathrm{ha}$, with a coefficient of variation of $17 \%$ (Table 1). The mass of plant-root residues of spring wheat in a layer of $0-40 \mathrm{~cm}$ was equal to $3.24 \mathrm{t} / \mathrm{ha}$, which is the minimum value among the studied variants. In oats on a natural agricultural background (without fertilizers), the mass of PRR was higher and reached $3.88 \mathrm{t} / \mathrm{ha}$.

The introduction of fertilizers at a dose of N40P75 kg/ha, on the planned yield of spring wheat of $3.0 \mathrm{t} / \mathrm{ha}$, had a positive effect on the grain harvest and the formation of the noncommodity part of the plants. The grain yield was $3.2 \mathrm{t} / \mathrm{ha}$, and the mass of plant-root residues was $3.69 \mathrm{t} / \mathrm{ha}$, which is $14 \%$ higher than the control values. Nevertheless, the calculation of the ratio of yield and mass of plant-root residues showed a decrease from 1.6 to 1.2 units, which indicates a decrease in the share of PRR in the spring wheat biomass. This trend continues for all the studied agricultural backgrounds. The introduction of fertilizers for the planned yield of $4.0 \mathrm{t} / \mathrm{ha}$ (N100P90) ensured the desired result. The mass of plant-root residues increased to $4.34 \mathrm{t} / \mathrm{ha}$, which is significantly higher than the previous version and control $\left(\mathrm{LSD}_{05}=0.24 \mathrm{t} / \mathrm{ha}\right)$. The mass of plant-root residues equaled the grain yield and amounted to $4.34 \mathrm{t} / \mathrm{ha}$. Thus, the creation of an agricultural background that ensures the planned yield of $4.0 \mathrm{t} / \mathrm{ha}$ of spring wheat grain leads to a decrease in the ratio grain:PRR by $34 \%$ relative to the control.

The most interesting were the variants with the doses of fertilizers N150P200 and $\mathrm{N} 185 \mathrm{P} 160 \mathrm{~kg} / \mathrm{ha}$, designed to obtain a grain yield of 5.0 and $6.0 \mathrm{t} / \mathrm{ha}$, respectively. As our studies have shown, the mass of plant-root residues remained almost at the same level 4.47-4.34 t/ha with the smallest significant difference equal to $0.24 \mathrm{t} / \mathrm{ha}$. The grain yield on these variants reached the planned values -5.3 and $5.7 \mathrm{t} / \mathrm{ha}$ with $\operatorname{LSD} 05=0.3 \mathrm{t} / \mathrm{ha}$. The ratio calculation showed that the mass of the roots became less than the formed crop by $20 \%$. Thus, it was found that in the conditions of the forest-steppe zone of Western Siberia, the mass of plant-root residues of spring wheat increases to $4.47 \mathrm{t} / \mathrm{ha}$. The results of the variance analysis showed that the share of participation of: mineral fertilizers is $47 \%$; weather conditions (moisture and soil temperature) - $25 \%$. The share of participation of unaccounted factors was $28 \%$. The formation of spring wheat crop yield over $4.0 \mathrm{t} / \mathrm{ha}$ occurs with an unchanged mass of plant-root residues. 
Table 1. The influence of mineral fertilizers on the mass of plant-root residues (PRR) of grain crops, 2017-2020.

\begin{tabular}{|c|c|c|c|c|}
\hline Crop & Fertilizer doses & $\begin{array}{c}\text { Grain yield, } \\
\text { t/ha }\end{array}$ & $\begin{array}{l}\text { Mass of plant-root } \\
\text { residues, } t / \text { ha }\end{array}$ & $\begin{array}{c}\text { Ratio of the main } \\
\text { product yield and } \\
\text { PRR }\end{array}$ \\
\hline \multirow{6}{*}{$\begin{array}{l}\text { Spring } \\
\text { wheat }\end{array}$} & $\begin{array}{l}\text { Control, without } \\
\text { fertilizers }\end{array}$ & 2.0 & 3.24 & $1: 1.6$ \\
\hline & N40P75 & 3.2 & 3.69 & $1: 1.2$ \\
\hline & N100P90 & 4.3 & 4.34 & $1: 1.0$ \\
\hline & N150P200 & 5.3 & 4.47 & $1: 0.8$ \\
\hline & N185P160 & 5.7 & 4.36 & $1: 0.8$ \\
\hline & $\mathrm{LSD}_{05}$ & 0.3 & 0,24 & - \\
\hline \multirow{6}{*}{ Oats } & $\begin{array}{l}\text { Control, without } \\
\text { fertilizers }\end{array}$ & 1.9 & 3.88 & $1: 2.0$ \\
\hline & $\mathrm{N} 60 \mathrm{P} 20$ & 2.9 & 4.74 & $1: 1.6$ \\
\hline & N90P40 & 4.1 & 5.96 & $1: 1.5$ \\
\hline & N150P60 & 5.1 & 6.04 & $1: 1.2$ \\
\hline & N200P80 & 6.0 & 5.77 & $1: 1,0$ \\
\hline & $\mathrm{LSD}_{05}$ & 0.2 & 0,21 & - \\
\hline
\end{tabular}

Note. $\mathrm{LSD}_{05}$ is the smallest significant difference for the $5 \%$ significance level.

The introduction of mineral fertilizers for the planned yield of oats up to $5.0 \mathrm{t} / \mathrm{ha}$ of grain $(\mathrm{N} 150 \mathrm{P} 60 \mathrm{~kg} / \mathrm{ha}$ ) contributes to an increase in the mass of plant-root residues from 3.88 (control) to $6.04 \mathrm{t} / \mathrm{ha}$. At the same time, there is also a change in the ratio of yield and PRR to 1:1.2 units. Further increase in the agricultural background (N200P80 kg/ha) caused a tendency to decrease the plant-root residues from 6.04 to $5.77 \mathrm{t} / \mathrm{ha}$ with the smallest significant difference equal to $0.21 \mathrm{t} / \mathrm{ha}$. Thus, there is a tendency to reduce the mass of oat roots at a high agricultural background. During long-term field experiments, it was found that in the conditions of the forest-steppe zone of Western Siberia, oats have a certain advantage over spring wheat, forming a more powerful root system.

Earlier studies have shown that in the conditions of the forest-steppe of the Trans-Urals, the mineralization of soil organic matter proceeds more actively during plowing $[13,14]$. Therefore, less plant residues remain for humification. Replacing plowing with non-tillage processing or switching to the No-till system can provide a deficit-free balance of humus of arable soils. For this purpose, it is necessary to know the features of the distribution of plant residues and aeration of plough horizon. The combination of this knowledge gives the prospect of creating a mathematical model of humus formation and carbon cycle in various agroecosystems.

Correlation analysis showed that the relationship between the productivity of grain crops and the mass of plant-root residues is very strong $(\mathrm{r}=0.87-0.95)$. This allows to calculate the regression and get a mathematical formula. The calculation was carried out by the least squares method. The equation corresponds to a power regression: $y=2.60 x^{0.32}$, where $y$ is the mass of plant-root residues, t/ha; $x$ is the yield of grain crops (spring wheat and oats). The determination index $\left(R^{2}\right)$ of the resulting equation was 0.93 . The average approximation error is $2.37 \%$. The critical Fischer's criterion $-\approx 10.13$; actual $-\approx 41.72$

During research, it was found that $85 \%$ of the mass of the root system of spring wheat and oats falls on a layer of $0-40 \mathrm{~cm}$. The rest is stretched in a layer of $40-100 \mathrm{~cm}$, so we do not take it into account. It has been established that grain crops (spring wheat and oats) in the Western Siberia do not fully develop the humus layer of chernozem due to unfavorable temperature conditions and water regime [15-16]. It is also impossible to reject the 
hypothesis of the influence of an over-compacted layer at a depth of 30-35 cm, which prevents the penetration of roots deep into the soil [17].

The root system of spring wheat under control (without fertilizers) is mainly formed in a layer of $0-10 \mathrm{~cm}-47 \%$ of the mass concentrated in the layer of $0-40 \mathrm{~cm}$. In layers of 10-20 and 20-30 cm, the proportion of roots was 24 and 26\%, respectively. At a depth of 30-40 $\mathrm{cm}$, the root mass did not exceed $3 \%$, which indicates the formation of a shallow root system. The application of mineral fertilizers at a dose of N40P75 kg/ha (planned yield of $3.0 \mathrm{t} / \mathrm{ha}$ ) did not affect the distribution of root residues in the layer of $0-40 \mathrm{~cm}$. A further increase in the level of mineral nutrition (N100P90) stimulated the development of the root system in the layer of $30-40 \mathrm{~cm}$, where their share increased to $12 \%$, which is 4 times higher than the control values.

The application of fertilizers N150P200 kg/ha did not have a significant effect on the nature of the distribution of the root system of spring wheat relative to the previous variant. However, the maximum level of the agricultural background (N200P80), calculated for a yield of $6.0 \mathrm{t} / \mathrm{ha}$, contributed to the distribution of root residues in the same proportions as in the control. It is necessary to note a decrease in the proportion of roots in the subsurface layer of 30-40 cm. This indicates the formation of the surface root system of spring wheat when applying high doses of fertilizers.

Table 2. Distribution of root residues of grain crops in a layer of 0-40 cm of arable chernozem, \%, 2017-2020.

\begin{tabular}{|c|c|c|c|c|c|}
\hline \multirow{3}{*}{ Crops } & \multirow{2}{*}{\begin{tabular}{c} 
Fertilizer doses \\
\cline { 2 - 5 }
\end{tabular}} & $0-10$ & $10-20$ & $20-30$ & $30-40$ \\
\hline \multirow{3}{*}{$\begin{array}{c}\text { Spring } \\
\text { wheat }\end{array}$} & $\begin{array}{c}\text { Control, without } \\
\text { fertilizers }\end{array}$ & 47 & 24 & 26 & 3 \\
\cline { 2 - 6 } & N40P75 & 49 & 25 & 21 & 5 \\
\cline { 2 - 6 } & N100P90 & 48 & 20 & 20 & 12 \\
\cline { 2 - 6 } & N150P200 & 43 & 27 & 20 & 10 \\
\cline { 2 - 6 } & N185P160 & 56 & 25 & 16 & 3 \\
\hline \multirow{4}{*}{ Oats } & LSD 05 & 4 & 2 & 3 & 2 \\
\cline { 2 - 6 } & Control, without & 53 & 23 & 17 & 7 \\
\cline { 2 - 6 } & fertilizers & 49 & 21 & 18 & 12 \\
\cline { 2 - 6 } & N60P20 & 45 & 15 & 24 & 16 \\
\cline { 2 - 6 } & N90P40 & 42 & 27 & 22 & 6 \\
\hline & N150P60 & 5 & 3 & 3 & 5 \\
\hline
\end{tabular}

Note. $\mathrm{LSD}_{05}$ is the smallest significant difference for the $5 \%$ significance level.

Oats, like spring wheat, belongs to the group of spring cereals, but has its own biological characteristics. The root system of oats is more powerful and is able to absorb hardly soluble nutrients, which makes it a valuable closing crop in the crop rotation. Currently, a large number of varieties with high ecological plasticity and resistance to adverse factors have been created [18, 19]. Therefore, oats are widely distributed throughout the territory of the Russian Federation.

Our research has shown that the root system of oats penetrates deeper. But the nature of the distribution by layers is similar to spring wheat. At the control, $49 \%$ of the roots fall on the layer of $0-10 \mathrm{~cm}$. With depth, the mass of root residues decreases, reaching a minimum in the layer of $30-40 \mathrm{~cm}$. The application of mineral fertilizers, even at a minimum dose (N60P20), stimulates the penetration of the root system deep into the soil - the mass of root residues in the layer of $30-40 \mathrm{~cm}$ increases to $12-16 \%$. The maximum agricultural 
background, designed to produce $6.0 \mathrm{t} /$ ha of grain, contributed to the reduction of the root system in the subsurface layer and the formation of its main mass in the plough horizon (0$30 \mathrm{~cm}$ ). Unlike spring wheat, a high agricultural background does not lead to an additional accumulation of oat root residues in the $0-10 \mathrm{~cm}$ layer and a decrease in their share in the 10-30 cm layer.

\section{Conclusion}

In the course of the conducted studies, it was found that there are no fundamental differences in the accumulation of plant-root residues in spring wheat and oats, and their averaged values can be used when developing a fertilizer system or calculating the balance of soil organic matter. On the natural agricultural background in the conditions of the forest-steppe zone of the Western Siberia, the mass of plant-root residues of spring wheat and oats is 3.24 and $3.88 \mathrm{t} / \mathrm{ha}$, and the ratio between yield and PRR is 1:1.6 and 1:1.2, respectively. With an increase in the level of mineral nutrition, the plant-root residues increase, reaching 4.47 and $6.04 \mathrm{t} / \mathrm{ha}$, but at the same time the ratio between grain and PRR decreases, reaching the ratio: for spring wheat $-1: 0.8$; for oats $-1: 1.0$ units. The mass of plant-root residues can be calculated using the following formula: $y=2.60 x^{0.32}$, where $y$ is the mass of plant-root residues, $\mathrm{t} / \mathrm{ha} ; x$ is the yield of grain crops (spring wheat and oats). The approximation coefficient of the regression equation is 0.93 .

The basic mass of the roots of grain crops (up to 50\%) grown on a natural agricultural background, concentrated in $0-40 \mathrm{~cm}$, is located in a layer of $0-10 \mathrm{~cm}$, while in $30-40 \mathrm{~cm}-$ $3-7 \%$. With an increase in the level of mineral nutrition, it helps to increase the root system in deeper layers, contributing to a more efficient absorption of water and nutrients in the humus layer.

\section{References}

1. O.M. Sheveleva, A.A. Bakharev, S.F. Sukhanova, IOP Conference Series: Earth and Environmental Science, 012023 (2019) DOI 10.1088/1755-1315/341/1/012023.

2. A.A. Kazak, Y.P. Loginov, Annals of Agri Bio Research 24 (2), 174-182 (2019)

3. A.V. Lyubimova, G.V. Tobolova, D.I. Eremin, I.G. Loskutov, Vavilov Journal of Genetics and Breeding 24(2), 123-130 (2020) DOI 10.18699/VJ20.607.

4. D.I. Eremin, Eurasian Soil Science 49 (5), 538-545 (2016) DOI 10.1134/S1064229316050033.

5. D. Eremina, MATEC Web of Conferences, 04016 (2018) DOI 10.1051/matecconf/201817004016

6. D. Eremina, IOP Conference Series: Earth and Environmental Science, 092007 (2018) DOI 10.1088/1755-1315/194/9/092007.

7. V.V. Kotov, K.E. Stekol'nikov, S.V. Tkachenko [et al.], Eurasian Soil Science 37(6), 618-623 (2004).

8. D.V. Eremina, D.I. Eremin, IOP Conference Series: Earth and Environmental Science, 012173 (2019) DOI 10.1088/1755-1315/403/1/012173.

9. D.V. Eremina, G.P. Selyukova, S. Selyukiva, Advances in Engineering Research, Tyumen, Atlantis Press, 169-173 (2018) DOI 10.2991/agrosmart-18.2018.33.

10. O.A. Sorokina, Eurasian Soil Science. 39(8), 813-819 (2006) DOI $10.1134 /$ S1064229306080023 
11. V.A. Khmelev, A.A. Tanasienko, Contemporary Problems of Ecology 2(6), 631-641 (2009). - DOI 10.1134/S1995425509060228.

12. N.O. Renev, V.A. Malchevsky, O.N. Renev, E.P. Renev, Research on Crops 22(S), 7981 (2021) DOI 10.31830/2348-7542.2021.019.

13. A.V. Chelovechkova, I.V. Komissarova, D.I. Eremin, IOP Conference Series: Earth and Environmental Science, 092004 (2018) DOI 10.1088/1755-1315/194/9/092004

14. D.I. Eremin, N.V. Fisunov, Epoch of Science 24, 37-45 (2020) DOI 10.24411/24093203-2020-12408.

15. D. Eremin, MATEC Web of Conferences, 02017 (2018) DOI 10.1051/matecconf/201817002017.

16. I. Kühling, D. Trautz, G. Broll, D. Redozubov, Soil \& Tillage Research 170, 43-52 (2017) DOI 10.1016/j.still.2017.02.009.

17. V. Rzaeva, IOP Conference Series: Earth and Environmental Science, 52079 (2021) DOI 10.1088/1755-1315/677/5/052079.

18. A.V. Ostapenko, G.V. Tobolova, Polymorphism of avenin species A.SATVA L., A.byzantina C. Koch. and A.strigosa Schreb, Plant Genetics, Genomics, Bioinformatics and Biotechnology, 39 (Novosibirsk: Federal Research Center Institute of Cytology and Genetics of the Siberian Branch of the Russian Academy of Sciences, 2015)

19. A.V. Lyubimova, D.I. Eremin, Advances in Engineering Research, Tyumen, Atlantis Press, 483-486 (2018) DOI 10.2991/agrosmart-18.2018.91. 